\section{Tumorigênese Hipofisária}

\section{RESUMO}

Os tumores hipofisários, adenomas na sua quase totalidade, representam de $10 \%$ a $15 \%$ das neoplasias intracranianas (1) e são encontrados em até $27 \%$ de autópsias não selecionadas, como achado incidental (2). Morfologicamente são classificados em microadenomas $(<1 \mathrm{~cm}$ de diâmetro) e macroadenomas, que podem ser circunscritos, invasivos e/ou expansivos. Do ponto de vista funcional, são divididos em adenomas secretores (de PRL, GH, ACTH, TSH, LH e FSH, podendo co-secretar dois ou mais hormônios) e clinicamente não secretores ou "não funcionantes". O diagnóstico é feito pelo fenótipo da hipersecreção (acromegalia, Cushing etc.) e, nos macroadenomas com efeito de massa, por hipopituitarismo e/ou distúrbios neurológicos, onde predominam as queixas visuais e cefaléia. Quanto aos mecanismos de tumorigênese hipofisária, a disputa entre causa primária hipotalâmica versus hipofisária ganhou força a favor da segunda graças às evidências da monoclonalidade dos tumores, juntamente com outros argumentos como a ausência de tecido hiperplásico circundando o adenoma cirurgicamente removido e a relativa independência do controle hipotalâmico. No entanto, admite-se que um papel permissivo do hipotálamo é importante para a progressão tumoral. Muitos mecanismos moleculares envolvidos na tumorigenese hipofisária já foram desvendados, incluindo oncogenes, genes supressores tumorais e fatores de crescimento, e serão descritos neste artigo de revisão. (Arq Bras Endocrinol Metab 2005;49/5:615-625)

Descritores: Neoplasias hipofisárias; Tumorigênese hipofisária; Oncogenes; Genes supressores fumorais; Fatores de crescimento

\section{ABSTRACT}

\section{Pituitary Tumorigenesis.}

Pituitary adenomas, almost invariably adenomas, account for $10 \%$ to $15 \%$ of all intracranial neoplasms and are incidentally detected in up to $27 \%$ of non selected autopsies. They are morphologically classified as microadenomas (diameter $<1 \mathrm{~cm}$ ) or macroadenomas, which can be enclosed, invasive and/or expansive. Functionally, they are classified as secreting adenomas (PRL, GH, ACTH, TSH, LH, and FSH, and those cosecreting two or more hormones), and clinically non secreting or "non functioning" tumors. Diagnosis is based on the hypersecretion phenotype (acromegaly, Cushing, etc), and on mass effect of macroadenomas leading to neurological disturbances, mainly visual complaints and headache. Pituitary tumorigenesis mechanisms include those of primary hypothalamic versus pituitary origin, the latter is supported by evidence of pituitary adenoma monoclonality, as well as the absence of hyperplastic tissue surrounding the surgically removed tumor, and the relative independence of tumor hypothalamic control. Nevertheless, a permissive role of the hypothalamus on tumor progression is also postulated. Several molecular mechanisms involved in pituitary tumorigenesis have been unraveled including oncogenes, tumor suppressor genes and growth factors involved in neoplastic development, and will be

\section{atualização}

\author{
Marcello D. Bronstein \\ Shlomo Melmed
}

Unidade de Neuroendocrinologia

$(M D B)$, Disciplina de

Endocrinologia do Departamento

de Clínica Médica do Hospital das

Clínicas da FMUSP, São Paulo,

SP; e Cedars-Sinai Medical Center

(SM), David Geffen School of

Medicine at the University of California, Los Angeles, California, USA. 


\section{described in this review. (Arq Bras Endocrinol Metab 2005;49/5:615-625)}

Keywords: Pituitary neoplasms; Pituitary tumorigenesis; Oncogenes; Tumor suppressor genes; Growth factors

$\mathrm{O}$ TUMORES hipofisários são NEOPLASIAS de ocorrência freqüente, representando de $10 \%$ a $15 \%$ de todas as neoplasias intracranianas em material cirúrgico e sendo encontrados em até $27 \%$ de autópsias não selecionadas (1). Apresentam amplo espectro de comportamento biológico: embora sejam em sua quase totalidade tumores histologicamente benignos (adenomas), cerca de $5 \%$ a $20 \%$ destas neoplasias apresentam comportamento invasivo (3). Carcinomas hipofisários, extremamente raros, não apresentam histologia diversa dos adenomas, tendo nas metástases à distância seu único critério diagnóstico (4).

A classificação dos tumores hipofisários é baseada nas suas características funcionais e morfológicas (tabela 1). Estas neoplasias são denominadas "funcionantes" quando produzem hormônios em quantidade suficiente para induzir manifestações clínicas, compreendendo, em ordem decrescente de freqüência: tumores lactotróficos (prolactinomas), tumores somatotróficos, tumores adrenocorticotróficos, e os raros tumores produtores de hormônios glicoprotéicos: gonadotrofinomas e tirotrofinomas. Os adenomas hipofisários também podem produzir mais de um hormônio, sendo mais freqüente a associação de hormônio de crescimento $(\mathrm{GH})$ e prolactina (PRL). As neoplasias hipofisárias que não secretam quantidades mensuráveis de hormônios intactos para a circulação, não levando portanto a quadro de hipersecreção hormonal, são denominadas adenomas clinicamente não secretores ou "não funcionantes". Morfologicamente, os tumores hipofisários são classificados como microadenomas (adenomas geralmente circunscritos com diâmetro inferior a $10 \mathrm{~mm}$ ) e macroadenomas (diâmetro superior a $10 \mathrm{~mm}$, podendo ser circunscritos à sela turca, expansivos ou invasivos) (5) (tabela 1). Os microadenomas são diagnosticados pelo quadro clínico ligado à sua hipersecreção hormonal ou, quando não-secretores, por achado incidental, através de imagem de cabeça realizada com outro propósito, como trauma de crânio, ou através de autópsia. Os macroadenomas são também diagnosticados por hiper ou hipo-secreção hormonal, quando presentes, ou através de manifestações neurológicas, principalmente as visuais e cefaléia, e também por achado incidental (incidentaloma). Podem levar à hipofunção hipofisária por comprimir a haste e, com isso, interferir no aporte dos hormônios hipotalâmicos para a adeno-hipófise, ou por destruir tecido hipofisário. Embora não existam diferenças histológicas características com os adenomas não invasivos, os tumores invasivos apresentam crescimento mais rápido, provocam erosão selar e infiltram estruturas vizinhas, tais como a dura mater, o osso e seio esfenoidais e o seio cavernoso (3). A morfologia dos adenomas hipofisários é verificada através de imagem e confirmada cirúrgica e anátomo-patologicamente. É importante frisar que o grau de invasão tumoral nem sempre é facilmente caracterizado: os adenomas hipofisários não possuem cápsula; na verdade, existe uma "pseudocápsula" constituída de células adeno-hipofisárias e de rede de reticulina condensada pertencentes ao lobo anterior não-adenomatoso. Desta forma, embora os macroadenomas sejam mais associados com invasão dural, também microadenomas podem ser invasivos (3).

Quais os mecanismos que levam à formação de tumores hipofisários, e por que alguns adenomas permanecem circunscritos e de pequenas dimensões, ao passo que outros tornam-se invasivos? Efetivamente, a etiopatogenia dos tumores hipofisários ainda é pouco conhecida. Tanto o hipotálamo como a hipófise têm sido indicados como sítio primário da tumorigênese da glândula (6). Com efeito, as primeiras idéias sobre patogênese dos tumores hipofisários provêm de bases fisiológicas dos anos 50 deste século, quando verificou-se que tumores hipofisários em roedores poderiam

Tabela 1. Classificação dos adenomas hipofisários.

\begin{tabular}{|c|c|c|}
\hline \multirow[t]{2}{*}{ Morfológica } & \multicolumn{2}{|c|}{ Funcional } \\
\hline & Secretores & Não secretores \\
\hline Microadenomas & PRL & $\begin{array}{l}\text { Sem imunoexpressão } \\
\text { (Adenomas "null cell") }\end{array}$ \\
\hline $\begin{array}{l}\text { Macroadenomas } \\
\text { Circunscritos } \\
\text { Invasivos } \\
\text { Expansivos }\end{array}$ & $\begin{array}{l}\text { GH } \\
\text { ACTH } \\
\text { LH/FSH } \\
\text { TSH } \\
\text { Mistos }\end{array}$ & $\begin{array}{l}\text { Com imunoexpressão de } \\
\text { um ou mais hormônios }\end{array}$ \\
\hline
\end{tabular}


ser induzidos por estímulo excessivo de mecanismos reguladores normais. Um exemplo é o desenvolvimento de tumores tirotrofocíticos em ratos, induzidos após período de hiperplasia originada por hipotiroidismo primário. Após fase de crescimento dependente da deficiência de hormônios tiroidianos, tais tumores perdiam o vínculo com a hipofunção tiroidiana e passavam a crescer independentemente (7). Em seres humanos, apenas pequena porcentagem de tumores tirotrofocíticos se desenvolveu em pacientes com hipotiroidismo primário (8), o que também se verifica para tumores produtores de gonadotrofinas em casos de hipogonadismo hipergonadotrófico (9). O que mais se observa nestes casos é o desenvolvimento de hiperplasia hipofisária, que geralmente regride quando se institui terapêutica de reposição (10) (figura 1). Outros argumentos a favor da etiopatogenia extrahipofisária baseiam-se nos raros casos de secreção anômala de fatores hipotalâmicos de liberação. O GHRH produzido por tumores ectópicos tais como carcinóides brônquicos e tumores pancreáticos ou por tumores hipotalâmicos como hamartomas e gangliocitomas, levam a estímulo das células somatotróficas e hiperplasia com conseqüente hipersecreção de GH, mas raramente se relacionam à formação de adenomas somatotróficos (11). Adicionalmente, pacientes com síndrome de Cushing causada por secreção ectópica de CRH não desenvolveram adenomas hipofisários, a despeito da presença de hiperplasia corticotrófica (12). Desta forma, embora um papel permissivo do hipotálamo não possa ser excluído, existem atualmente evidências que apontam para mecanismo hipofisário primário para o desenvolvimento tumoral. Um dos principais argumentos nesta direção vem da verificação, através da técnica da inativação do cromossomo $\mathrm{X}$, de que os adenomas hipofisários têm origem monoclonal (13). Adicionalmente, o exame histológico dos adenomas ressecados cirurgicamente não revela tecido hiperplásico circundando o tumor, e as secreções hormonais destas neoplasias são relativamente independentes do controle hipotalâmico (15). Com efeito, pacientes portadores de adenomas hipofisários freqüentemente mostram respostas ausentes ou anômalas de hormônios hipofisários aos testes dinâmicos, respostas estas que geralmente se normalizam quando o tumor é removido cirurgicamente. Estes dados são fortes indicadores de que os adenomas hipofisários resultam da expansão clonal de um tipo de célula adenohipofisária que sofreu mutação. Entretanto, a redução de volume dos prolactinomas verificada com o emprego de drogas agonistas dopaminérgicas (16) e de tumores produtores de GH com análogos da somatostatina (16) e, ao contrário, o crescimento de adenomas produtores de ACTH após adrenalectomia bilateral (síndrome de Nelson) (18) são demonstrações claras da importância dos neurotransmissores e hormônios peptídicos hipotalâmicos no controle da progressão tumoral. Também fatores de crescimento, como o fator de crescimento epidérmico (EGF) e o fator de crescimento de fibroblastos básico (FGF-2) podem, através da família de receptores da tirosino-quinase, influenciar na regulação e na diferenciação celular $(19,20)$. Verificou-se que alguns destes fatores podem, juntamente com seus receptores, ser expressos em tumores hipofisários.
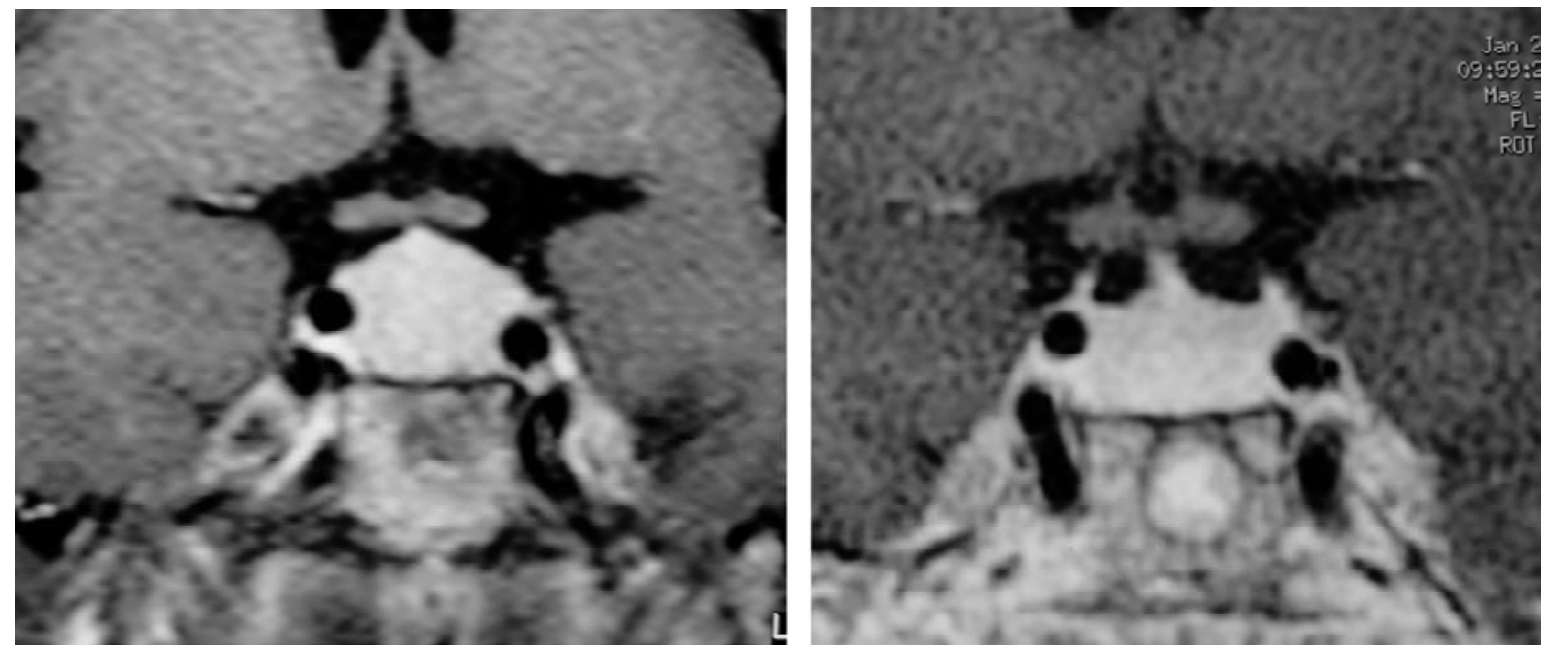

Figura 1. Hiperplasia tirotrofocítica hipofisária decorrente da perda da retro-alimentação pelo hipotiroidismo primário (E), mostrando grande redução durante reposição com L-tiroxina (D). 
Muitas mutações podem estar envolvidas na tumorigênese hipofisária, tanto ativadoras de genes promotores quanto inativadoras de genes supressores tumorais (6). No primeiro caso, um proto-oncogene (gene normal envolvido no controle da proliferação e diferenciação celular) é ativado através de mutação. Um importante exemplo de mutação ativadora são as mutações em ponto (point mutations) do gene que codifica a proteína Gs. Elas ocorrem em até $40 \%$ dos adenomas produtores de GH (21), em cerca de 10\% dos adenomas clinicamente não-secretores $(22) \mathrm{e} \mathrm{em}$ 6\% dos adenomas secretores de ACTH (23). Também mutações em ponto de proto-oncogenes ras, estruturalmente relacionados às proteínas $\mathrm{G}$, foram descritas em tumores hipofisários. Sabe-se que estas mutações, que convertem os proto-oncogenes em oncogenes ativos, são comumente identificadas em diferentes neoplasias malignas humanas (24). No entanto, somente uma mutação do gene $\mathrm{H}$-ras em um prolactinoma agressivo foi verificada em 4 estudos que examinaram mais de 200 adenomas hipofisários secretores e não-secretores (25). Curiosamente, mutações $\mathrm{H}$-ras foram identificadas em metástases de carcinomas hipofisários em 3 de 5 pacientes estudados, mas não nos tumores primários (26).

Em relação à inativação de genes supressores tumorais, elas geralmente seguem o modelo dos dois "golpes" de Knudson (figura 2). A condição mais descrita em adenomas hipofisários é a perda de heterozigosidade envolvendo a região cromossômica l lql3 na neoplasia endócrina múltipla tipo l (MEN 1) (27) e também na acromegalia/gigantismo familiar isolada (28). Curiosamente, ao passo que mais de $80 \%$ dos pacientes portadores de MEN l apresentam mutações germinativas na região codificadora ou nas junções exon-intrônicas do gene que codifica a "menin", tais mutações não foram verificadas em pacientes com acrogigantismo familiar isolado (28). Isto sugere que um gene supressor tumoral, localizado na região $1 \mathrm{lq} 13$ mas distinto do gene da "menin", esteja envolvido na patogênese desta síndrome familiar isolada. Também cerca de $20 \%$ dos adenomas hipofisários esporádicos associam-se a perda de heterozigosidade na região $1 \mathrm{lql} 3$, mas também não ligadas a mutações no gene da "menin". Outro gene supressor tumoral que pode estar associado à tumorigênese hipofisária é o nm23 (purine-binding factor gene). Recentemente, a expressão do RNA do nm23 foi estudada em 22 tumores hipofisários, tendo sido constatada redução significativa da expressão da isoforma $\mathrm{H} 2$ e da imunorreatividade de sua proteína em adenomas invasivos (29). Entretanto, estes

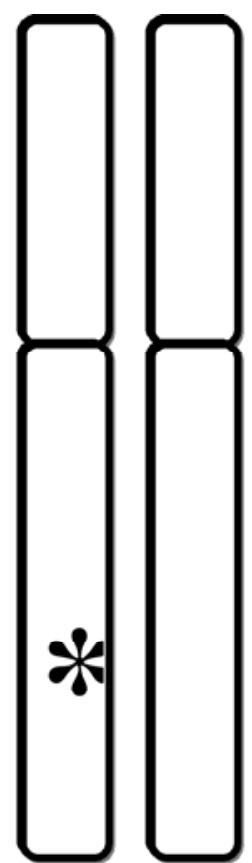

1o evento mutação germinativa

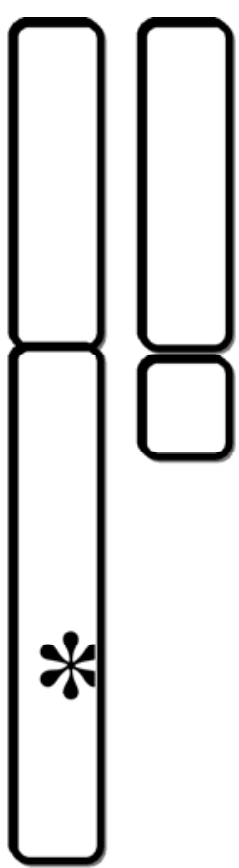

2o evento deleção somática
Figura 2. Teoria dos dois eventos de Knudson: A expressão fenotípica da mutação germinativa somente é evidenciada após deleção somática no segundo alelo.

tumores não expressaram alterações estruturais do gene nm23. Finalmente, verificou-se em tumores hipofisários de camundongos alterações heterozigóticas do gene do retinoblastoma (RB), cujo produto $\mathrm{RB}$ tem papel importante na regulação do ciclo celular (30). No entanto, estas mutações não foram verificadas em seres humanos (31). Por outro lado, foi verificada perda de heterozigosidade na proximidade do locus do gene de suscetibilidade para o RB no cromossomo $13 \mathrm{q}$ em tumores hipofisários humanos malignos ou muito invasivos e suas respectivas metástases. Embora tenha sido detectada imunorreatividade para a proteína $\mathrm{RB}$ nestes tumores, a expressão do mRNA do RB não foi demonstrada. Desta forma, mutações em outros genes supressores tumorais localizados próximos ao RB poderiam estar envolvidas no controle da proliferação celular na espécie humana (6). A inativação ("silenciamento") por metilação de outro gene supressor tumoral, o pl6, muito ligado à função do gene do RB, também tem sido implicada na etiopatogenia dos tumores hipofisários (6). Alterações em outro gene supressor tumoral, o p27, também parecem estar envolvidas na tumorigênese hipofisária (32). Curiosamente, o gene supressor p53, freqüentemente 
mutado em tumores humanos, não parece sofrer mutação em adenomas hipofisários (33).

Foi isolado de tumores hipofisários GH4 de ratos, pela técnica de differential RNA display, um novo gene transformador tumoral (pituitary tumor transforming gene - PTTG) que codifica uma proteína com 199 aminoácidos (34). O mRNA deste gene também é expresso em testículo normal de ratos adultos e em fígado fetal do animal. A hiperexpressão do cDNA do PTTG murino em células NIH3T3 causou transformação celular in vitro e indução in vivo de tumores em camundongos atímicos (34). Participamos da clonagem molecular do correspondente humano do PTTG, utilizando o cDNA do PTTG murino como sonda de prospecção de uma biblioteca de cDNA fetal humano (35). Os cDNAs humano e murino, bem como suas respectivas proteínas, apresentam expressiva homologia. Assim como o seu homólogo, o PTTG humano induziu transformação celular in vitro e in vivo, comportamento sugestivo de um oncogene. $\mathrm{O}$ PTTG expressou-se em alguns tecidos humanos normais, principalmente testículo, timo, cólon e intestino delgado, sugerindo que pode também estar envolvido no controle de funções normais de alguns órgãos. Ele também apresentou abundante expressão em diversas linhagens celulares malignas humanas (35), e existe evidência de correlação entre a expressão do PTTG e o grau de agressividade em tumores de cólon (36). O PTTG humano é localizado no cromossomo 5q33, região reconhecidamente ligada ao desenvolvimento de várias doenças malignas. A maior parte de 53 adenomas hipofisários testados através de RT-PCR apresentaram expressão aumentada do PTTG quando comparados com hipófises normais, havendo correlação positiva entre o grau de expressão e o de invasão tumoral em prolactinomas e adenomas produtores de $\mathrm{GH}$ (37). O mecanismo de ação do PTTG não é totalmente conhecido, mas existem evidências de que este oncogene induz, por interação parácrina, a expressão do fator de crescimento de fibroblastos básico ou tipo 2 (FGF-2), conhecido mediador do crescimento celular e da angiogênese, e portanto da patogênese tumoral (38).

O PTTG é uma securina de mamíferos, tendo participação importante na mitose ligando-se e inibindo as separinas, que clivam a ligação das cromátides irmãs pela cohesina (39). O PTTG é degradado no final da metáfase, permitindo separação igual das cromátides irmãs (40). A hiperexpressão do PTTG promove aneuploidia inibindo a segregação harmônica das cromátides e aumentando o número de células aneuplóides, levando assim à instabilidade genômica (41). Desta forma, o PTTG apresenta propriedades de oncogene, uma vez que a sua hiperexpressão causa transformação celular e aneuploidia. Paradoxalmente, a presença de núcleos anormais, aumento de aneuploidia e divisão centromérica prematura também é observada em fibroblastos derivados de camundongos "knock-out" (PTTG-/-). Desta forma, tanto excesso de PTTG como observado em tumores quanto perda do mesmo leva à ruptura do ciclo celular e aneuploidia. Estas características apontam o PTTG como um gene "zelador", que assegura estabilidade genômica. Ainda não está estabelecido se a aneuploidia é uma causa primária ou conseqüência da transformação celular. No entanto, a despeito do aumento de aneuploidia, a incidência de tumores hipofisários em camundongos "knock-out" para PTTG é notavelmente inferior à de animais heterozigotos para $\mathrm{Rb}(6)$.

Desta forma, os mecanismos de tumorigênese hipofisária mais conhecidos são relacionados a mutações ativadoras e hiperexpressão de oncogenes (Proteína G, PTTG) e mutações inativadoras de genes supressores tumorais, das quais a perda de heterozigosidade em llql3 é a mais bem estabelecida. Adicionalmente, a redução de expressão da proteína do gene $\mathrm{nm} 23$ e a perda de heterozigosidade em 13q14 podem estar implicados no desenvolvimento de tumores hipofisários, particularmente os mais agressivos. Embora os mecanismos básicos sejam comuns para todos os tipos tumorais, vamos particularizar alguns aspectos de cada grupo.

\section{Tumores somatotróficos}

Os somatotrofos compreendem cerca de $40 \%$ das células adeno-hipofisárias. A hipersecreção de $\mathrm{GH}$ leva a quadro clínico de acromegalia e/ou gigantismo. Adenomas somatotróficos são responsáveis por $99 \%$ dos casos; raramente a produção excessiva de GH é decorrente de secreção anormal do hormônio liberador do GH (GHRH) por tumores hipotalâmicos (eutópica) ou por tumores extracranianos, principalmente pulmonares e pancreáticos (ectópica) (11).

A síntese e secreção do GH são moduladas pelo GHRH, cujo receptor pertence à família dos receptores acoplados à proteína $\mathrm{G}$. Mutações em ponto da sub-unidade $\alpha$ da proteína $G$ podem levar à ativação ligante-independente (constitutiva) do receptor, com elevação do cAMP e hipersecreção de GH (figura 3). Estas mutações ocorrem em um sub-grupo de adenomas somatotróficos, com prevalência variável: $10 \%$ em japoneses, 30 a $40 \%$ em caucasianos e coreanos. Curiosamente, os adenomas somatotróficos associados a mutações na proteína G são geralmente do tipo densamente granulado à imuno-histoquimica, menos 


\section{Somatotrofinomas: Tumorigênese}

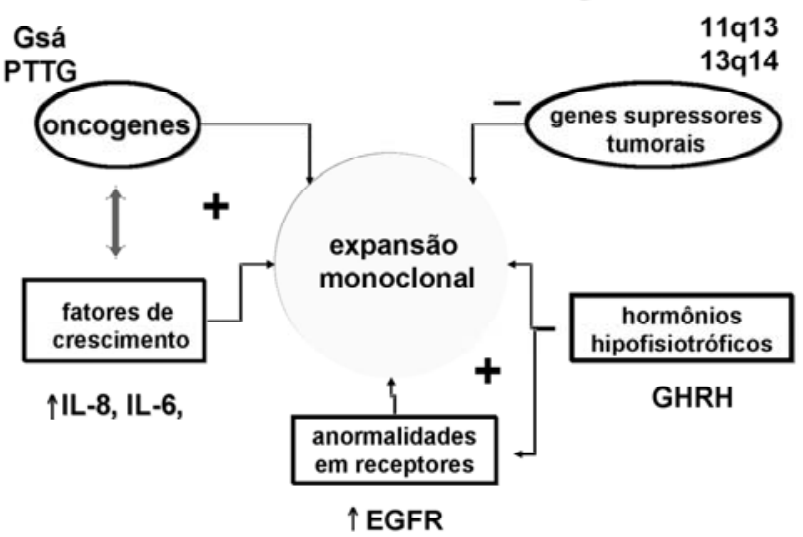

Figura 3. Principais eventos relacionados à tumorigênese somatotrófica.

agressivos do que os esparsamente granulados. O mecanismo pelo qual tais mutações contribuem para a diferença no comportamento tumoral dos somatotrofos ainda é desconhecido.

A expressão do fator de crescimento epitelial (EGF) e de seu receptor (EGF-R) foi estudada em diferentes tipos de adenomas hipofisários humanos, verificando-se que os adenomas somatotróficos e os agressivos adenomas clinicamente não secretores do sub-tipo silencioso 3 foram os que mais abundantemente expressaram o mRNA do EGF-R (19). Adicionalmente, tumores de pacientes acromegálicos com recidiva apresentaram níveis significantemente mais elevados do mRNA do EGF-R quando comparados com adenomas de pacientes sem doença recidivante. Desta forma, é provável que o EGF seja relacionado com a agressividade de tumores hipofisários, particularmente os secretores de GH. Como já mencionado, também a expressão do PTTG correlacionou-se com o grau de invasão dos adenomas somatotróficos.

\section{Somatotrofinomas de ocorrência familiar}

A acromegalia/gigantismo pode ocorrer associada a duas síndromes familiares de neoplasia endócrina múltipla, a já referida MEN 1 e o complexo de Carney (42). Este último é caracterizado pela associação de manifestações tão diversas como: mixomas (cardíaco, de pele, de mama), pigmentação mucocutânea, tumores adrenais (displasia nodular pigmentada), tiroidianos, testiculares e hipofisários. Os somatotrofinomas, geralmente macroadenomas, estão presentes em $10 \%$ a $21 \%$ dos pacientes portadores do complexo de Carney, podendo estar associados a gigantismo ou acromegalia (43). Embora não se conheça o defeito genético responsável por esta síndrome, o complexo de Carney foi mapeado por análise de "linkage" aos cromossomos 2pl5-16 e 17q 23-24 em diferentes famílias $(44,45)$. Adicionalmente, existem evidências recentes de que a região 2 p 16 pode estar envolvida na patogênese do acro-gigantismo familiar isolado (46). Curiosamente, pacientes com acromegalia familiar isolada (não ligada à MEN 1) também podem apresentar perda de heterozigosidade na região $11 \mathrm{q} 13$, mas nestes casos não foram detectadas mutações do gene da "menin" (28). Desta forma, é provável que mutação em um outro gene próximo ao locus da MEN 1 esteja seja o mecanismo somático desta entidade. A figura 3 resume os principais eventos conhecidos relacionados à etiopatogenia dos tumores somatotróficos.

\section{Prolactinomas}

Os adenomas produtores de prolactina são os mais prevalentes dentre os adenomas hipofisários secretores e também os mais comuns (> 50\%) dentre os tumores da hipófise associados à MEN 1 (figura 4). No entanto, a ocorrência de prolactinomas familiares isolados não é tão bem estabelecida com no caso do acrogigantismo (47).

Os mecanismos que levam ao desenvolvimento dos adenomas lactotróficos não são bem estabelecidos. Dentre os mais relacionados estão o PTTG (38), e o heparin-binding secretory transforming gene (hst) (48), ambos provavelmente atuando via fatores de crescimento de fibroblastos (FGF-2 e FGF-4, respectivamente) induzindo angiogênese. Os estrógenos parecem exercer papel fundamental nestes mecanismos, já que drogas com ação anti-estrogênica inibem a expressão do PTTG em prolactinomas in vitro e o seu crescimento in vivo (49). O FGF-4, proteína codifica-

\section{Prolactinomas: Tumorigênese}

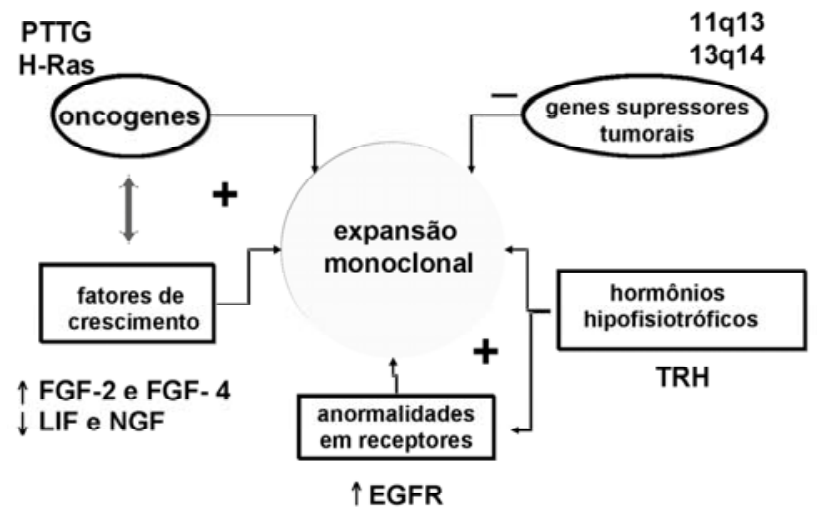

Figura 4. Principais eventos relacionados à tumorigênese lactotrófica.

Arq Bras Endocrinol Metab vol $49 n^{\circ} 5$ Outubro 2005 
da pelo heparin-binding secretory transforming gene (bst), tem potente atividade angiogênica e é expresso em prolactinomas. $\mathrm{O}$ oncogene hst transfectado (ou a própria proteína FGF-4) estimula a secreção de prolactina, e a hiperexpressão do hst é associada com a agressividade de tumores experimentais (50). Foi demonstrada recentemente imunoexpressão da FGF-4 em três de cinco prolactinomas invasivos e em apenas dois de nove adenomas lactotróficos não invasivos (48).

A redução na inibição dopaminérgica parece exercer papel ao menos permissivo no desenvolvimento de prolactinomas. Sarkar e cols., ainda na década de 80 (45), verificaram lesões em neurônios dopaminérgicos tubero-infundibulares de ratas portadoras de prolactinomas. Recentemente, vários estudos têm demonstrado o desenvolvimento de prolactinomas em camundongos com knock-out do receptor D2, sendo este fenótipo mais severo e de mais rápida evolução nas fêmeas e nos animais tratados com estrogênios. No entanto, até o presente não foram encontradas mutações "naturais" no gene do receptor D2 (22). Outros mecanismos potencialmente envolvidos na tumorigênese dos prolactinomas são a redução na expressão da citoquina leukemia inhibitory factor (LIF) (3) e do fator de crescimento do nervo (NGF) (20) e o aumento na expressão da bone morphogenetic protein 4 (BMP-4) (29) e do high mobility group A2 gene (HMGA2) (30).

Com relação a outros fatores relacionados à agressividade dos prolactinomas, somente uma mutação do gene H-ras em um prolactinoma invasivo foi descrita em estudos que examinaram mais de 200 adenomas hipofisários secretores e não secretores. Adicionalmente, tal mutação foi encontrada em metástase de carcinoma lactotrófico mas não no tumor primitivo. Prolactinomas resistentes aos agonistas dopaminérgicos como a bromocriptina têm freqüentemente comportamento agressivo, podendo ser inclusive malignos. No entanto, pouco se conhece quanto ao mecanismo desta resistência além da redução da densidade dos receptores dopaminérgicos da classe D2 e da redução da relação entre a isoforma curta (D2S) e a isoforma longa (D2L) destes receptores. A redução da expressão do fator de crescimento do nervo (NGF) também já foi relacionada a prolactinomas resistentes.

Os prolactinomas associados à síndrome de neoplasia endócrina múltipla tipo l (NEM l) que apresentam mutações inativadoras caracterizadas por perda de heterozigosidade no locus 11 ql3 e mutações no gene que codifica a "menin" tendem a ser mais agressivos do que os prolactinomas esporádicos. É interessante ressaltar que cerca de $15 \%$ dos prolactino- mas esporádicos apresentam perda de heterozigosidade 11 ql3, mas sem mutações detectadas no gene que codifica a "menin".

\section{Adenomas corticotróficos}

As células produtoras de ACTH constituem de 15 a $20 \%$ da população adeno-hipofisária. Cerca de 10 a $15 \%$ dos adenomas hipofisários são corticotróficos, grande parte constituída por microadenomas. Embora $5 \%$ destes sejam silenciosos, a maior parte hipersecreta ACTH, levando à doença de Cushing, causa mais freqüente de hipercortisolismo. Do ponto de vista de sua etiopatogenia, não se conhece a razão da maior parte destes tumores serem microadenomas. A participação hipotalâmica deve ser considerada na progressão para adenomas mais agressivos, já que cerca de $30 \%$ dos pacientes tratados por adrenalectomia bilateral desenvolvem tumores invasivos (síndrome de Nelson) por perderem o efeito frenador dos níveis elevados de cortisol sobre o eixo CRH-ACTH, não mantido pelas doses de reposição de corticosteróides naturais ou sintéticos. É justamente o fato dos adenomas corticotróficos manterem semelhanças de retroalimentação com o corticotrofo normal, em nível mais elevado, que torna o estudo destes tumores muito atraente para o entendimento do processo de oncogênese: pode-se inferir que o defeito somático que ocorre no clone corticotrófico seja sutil.

Existem defeitos comuns com outros tipos tumorais hipofisários: mutações ativadoras da proteína G são descritas em cerca de $6 \%$ dos adenomas corticotróficos. Também podem estar associados à MEN 1, embora em freqüência menor do que os prolactinomas e somatotrofinomas. A expressão do PTTG também está aumentada neste tipo tumoral. Adicionalmente, existem descrições de eventos diretamente relacionados à etiopatogenia dos adenomas produtores de ACTH (figura 5).

Hiperexpressão dos receptores de CRH e de V3R - Sabemos que tanto o CRH como a vasopressina estimulam a liberação de ACTH. Estudos recentes demonstram que adenomas corticotróficos exibem hiperexpressão nos receptores de CRH (CRH-R) e do sub-tipo 3 da vasopressina (V3R) em comparação com corticotrofos normais. Ambos os receptores são da família da proteína G. No entanto, não foram detectadas mutações nas regiões codificadoras dos genes CRH-R e V3R, fato que não aponta para ativação constitutiva da transdução do sinal. Desta forma, não está claro se a hiperexpressão destes receptores atua como causa de tumorigênese corticotrófica ou seja conseqüência do hipercortisolismo decorrente destes tumores. 


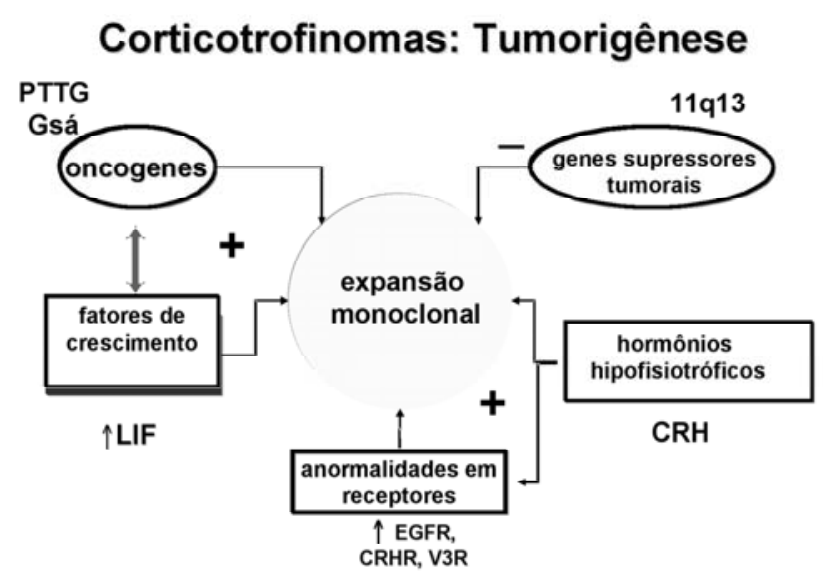

Figura 5. Principais eventos relacionados à tumorigênese adrenocorticotrófica.

Aumento da expressão do fator inibidor de leucemia (LIF) - O LIF é membro da família das citoquinas que incluem, entre outras, as interleucinas $1 \mathrm{e}$ 6. Induz, atuando através de receptor próprio (LIFR), a secreção de ACTH, e potencializa os efeitos do CRH. Estudos têm sugerido participação do LIF na diferenciação do corticotrofo. Recentemente foi demonstrada hiperplasia corticotrófica e fenótipo cushingóide em camundongos transgênicos hiperexpressando LIF. No entanto, não está clara a participação desta citoquina na tumorigênese corticotrófica.

Receptor de glicocorticóides (GR) Mutações no gene que codifica o GR levando à alteração na sua função poderiam contribuir para a resistência relativa aos glicocorticóides verificada nos adenomas corticotróficos. No entanto, com exceção do tecido tumoral de um paciente com síndrome de Nelson, não foram verificadas mutações no gene do GR em outro pacientes com esta síndrome, e em portadores de doença de Cushing, inclusive em um caso de carcinoma produtor de ACTH. Estes dados sugerem que mutações no gene do GR não são comumente envolvidas na tumorigênese corticotrófica. Entretanto, estudo recente sugere que deleções neste gene podem influir na etiopatogenia da doença de Cushing: $30 \%$ dos tumores corticotróficos examinados para perda de heterozigosidade em 5 polimorfismos conhecidos do gene do GR apresentavam deleções monoalélicas. $\mathrm{O}$ significado funcional destas deleções nestes tumores não foi estabelecido, já que não foram encontradas mutações no outro alelo e não foram efetuados estudos de expressão para caracterizar a haploinsuficiência do GR. Adicionalmente, Antonini e cols. sugerem que polimorfismos no gene do GR podem conferir vantagem seletiva para a tumorigênese dos corticotrofinomas, embora não tenham verificado relação entre os polimorfismos e a apresentação clínica, dimensões tumorais e resultados cirúrgicos dos pacientes com doença de Cushing.

Um recente estudo da expressão do EGFR em tumores hipofisários verificou que a maior expressão deste receptor foi detectada em adenomas corticotróficos. É possível que o envolvimento do EGFR na tumorigênese corticotrófica se faça através da redução de expressão do p27/Kipl.

\section{Adenomas Clinicamente Não Secretores}

Representam cerca de 25\% dos tumores hipofisários e constituem classe heterogênea dentro destes, já que, mesmo sem secretar quantidades apreciáveis de hormônios adeno-hipofisários, podem imunoexpressá-los. Desta forma, é razoável admitirmos que um adenoma somatotrófico silencioso guarda características semelhantes aos tumores que levam ao fenótipo acromegálico. No entanto, a maior parte dos adenomas clinicamente não secretores são gonadotrofinomas: mesmo aqueles que não apresentam imunoexpressão hormonal (null cell adenomas) são provavelmente de linhagem gonadotrófica: estudos de hibridação in situ mostram que estes tumores freqüentemente expressam o mRNA do FSH/LH, e muitos deles secretam subunidade $\alpha$, parte da molécula comum aos hormônios gonadotróficos. Existem descrições de mutações ativadoras na proteína $\mathrm{G}$ em adenomas não funcionantes, mas não são descritas características imuno-histoquímicas dos casos positivos para estas mutações. Da mesma forma, estes tumores podem estar associados à MEN 1. Como já referido, tumores mais agressivos correlacionaram-se negativamente com a expressão do mRNA do nm23 e de sua proteína. O sub-tipo silencioso 1 destes adenomas, muito invasivo, apresentou aumento da expressão do mRNA do EGF-R. Curiosamente, ao contrário dos prolactinomas e somatotrofinomas, não houve correlação entre a expressão do PTTG e o grau de invasibilidade dos adenomas não secretores estudados. Pagotto e cols. observaram em adenomas não funcionantes perda da expressão do gene ZAC, muito expresso na hipófise anterior, e que codifica uma proteína que concomitantemente induz apoptose e parada do ciclo celular. Finalmente, verificou-se diminuição da expressão dos receptores nucleares de esteróides e de hormônios tiroidianos em adenomas não funcionantes, mas o seu significado funcional não está estabelecido.

Em resumo, embora muitos dos mecanismos envolvidos na tumorigênese hipofisária ainda não estejam elucidados, a figura 7 sumariza os conhecimentos atuais: estes tumores, na maioria adenomas, resultam 


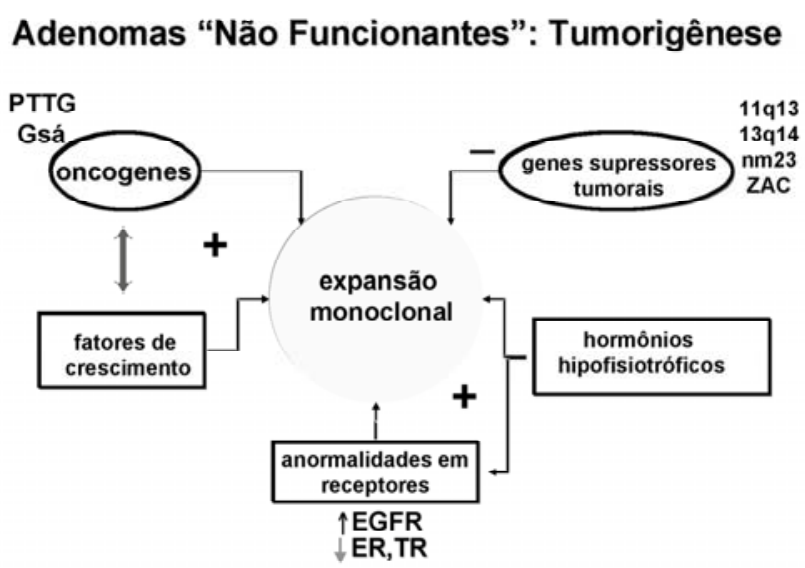

Figura 6. Principais eventos relacionados à tumorigênese dos adenomas não-funcionantes.

da expansão monoclonal de células transformadas. Desta transformação e proliferação participam oncogenes (em interação com fatores de crescimento celular), e genes supressores tumorais mutados. Apesar das evidências atuais indicarem gênese hipofisária primária, a participação do hipotálamo, através de seus hormônios hipofisiotróficos, é fator relevante. Eles podem atuar na proliferação de um clone celular transformado através de mecanismos regulatórios normais $(\mathrm{CRH}$ atuando em corticotrofos) ou anormais (TRH atuando em somatotrofos). Alternativamente, e com menos freqüência, a transformação clonal poderia ocorrer na hipófise previamente hiperplasiada.

\section{REFERÊNCIAS}

1. Kovacs K, Horvarth E. Pathology of pituitary tumors. Endocrinol Metab Clin North Am 1987;16:529-51.

2. Molitch ME. Pituitary incidentalomas. Endocrinol Metab Clin North Am 1997;6:725-40.

3. Scheithauer BW, Kovacs KT, Laws ER Jr, Randall RV. Pathology of invasive pituitary tumors with special reference to functional classification. J Neurosurg 1986;65:733-44

4. Pernicone PJ, Scheithauer BW, Sebo TJ, Kovacs KT, Horvath E, Young WF Jr, et al. Pituitary carcinoma: a clinicopathologic study of 15 cases. Cancer 1997;15;79:804-12.

5. Hardy J. Transsphenoidal surgery of hypersecreting pituitary tumors. In: Kohler PO, Ross GT, eds. Diagnosis And Treatment Of Pituitary Tumors. Amsterdam:International Congress Series, 1973, 303.p. 179.

6. Melmed S. Mechanisms for pituitary tumorigenesis: the plastic pituitary. J Clin Invest 2003; 1 12:1603-18.

7. Furth J. Experimental pituitary tumors. Rec Progr Horm Res 1955;11:221-49.
8. Katz MS, Gregerman RI, Horvath E, Kovacs K, Ezrin C. Thyrotroph cell adenoma of the human pituitary gland associated with primary hypothyroidism: clinical and morphological features. Acta Endocrinol (Copenh) 1980:95:41-8.

9. Kovacs K, Horvath E, Rewcastle NB, Ezrin C. Gonadotroph cell adenoma of the pituitary in women with long-standing hypogonadism. Arch Gynecol 1980;229:57-65.

10. Bhansali A, Sreenivasulu P, Khandelwal N, Masoodi SR. Reversibility of thyrotroph hyperplasia after L-thyroxine replacement therapy in patients with juvenile primary hypothyroidism. J Pediatr Endocrinol Metab 2004; 17:655-61.

11. Sano T, Asa SL, Kovacs K. Growth hormone-releasing hormone-producing tumors: clinical, biochemical, and morphological manifestations. Endocr Rev 1988;9:35773.

12. Carey RM, Varma SK, Drake CR Jr, Thorner MO, Kovacs $\mathrm{K}$, Rivier J, et al. Ectopic secretion of corticotropinreleasing factor as a cause of Cushing's syndrome. A clinical, morphologic, and biochemical study. N Engl J Med 1984;311:13-20.

13. Herman V, Fagin J, Gonsky R, Kovacs K, Melmed S. Monoclonal origin of pituitary adenomas. J Clin Endocrinol Metab 1990;71:1427-33.

14. Alexander JM, Biller BMK, Bikkal H, Zervas NT, Arnold A, Klibanski A. Clinically nonfunctioning pituitary tumors are monoclonal in origin. J Clin Invest 1990;86:336-40.

15. Shimon I, Melmed S. Pituitary tumor pathogenesis. J Clin Endocrinol Metab 1997;82:1675-81.

16. Bronstein MD, Cardim CS, Marino Jr R. Short-term management of macroprolactinomas with a new injectable form of bromocriptine. Surg Neurol 1987;28:31-7.

17. Jallad RS, Musolino NR, Salgado LR, Bronstein MD. Treatment of acromegaly with octreotide-LAR: Extensive experience in a Brazilian institution. Clin Endocrinol 2005;63:168-75.

18. Nelson DH, Meakin JW, Thorn GW. ACTH-producing pituitary tumors following adrenalectomy for Cushing's syndrome. Ann Intern Med 1960;52:560-9.

19. LeRiche VK, Asa SL, Ezzat S. Epidermal growth factor and its receptor (EGF-R) in human pituitary adenomas: EGF$R$ correlates with tumor aggressiveness. J Clin Endocrinol Metab 1996;81:656-62.

20. Abbass SA, Asa SL, Ezzat S. Altered expression of fibroblast growth factor receptors in human pituitary adenomas. J Clin Endocrinol Metab 1997;82:1 160-6.

21. Spada A, Arosio M, Bochicchio D, Bazzoni N, Vallar L, Bassetti $M$, et al. Clinical, biochemical, and morphological correlates in patients bearing growth hormonesecreting pituitary tumors with or without constitutively active adenylyl cyclase. J Clin Endocrinol Metab 1990;71:1421-6.

22. Williamson EA, Daniels M, Foster S, Kelly WF, Kendall-TayIor P, Harris PE. Gs alpha and Gi2 alpha mutations in clinically non-functioning pituitary tumours. Clin Endocrinol (Oxf) 1994;41:815-20.

23. Williamson EA, Ince PG, Harrison D, Kendall-Taylor $P$, Harris PE. G-protein mutations in human pituitary 
adrenocorticotrophic hormone-secreting adenomas. Eur J Clin Invest 1995;25(2):128-31.

24. Bos JL. ras oncogenes in human cancer: a review. Cancer Res 1989;49:4682-9.

25. Karga HJ, Alexander JM, Hedley-Whyte ET, Klibanski A, Jameson JL. Ras mutations in human pituitary tumors. $\mathbf{J}$ Clin Endocrinol Metab 1992;74:914-9.

26. Pei L, Melmed S, Scheithauer B, Kovacs K, Prager D. Hras mutations in human pituitary carcinoma metastases. J Clin Endocrinol Metab 1994;78:842-6.

27. Bale AE, Norton JA, Wong EL, Fryburg JS, Maton PN, Oldfield $\mathrm{EH}$, et al. Allelic loss on chromosome 11 in hereditary and sporadic tumors related to familial multiple endocrine neoplasia type 1. Cancer Res 1991;51:1154-

28. Gadelha MR, Prezant TR, Une KN, Glick RP, Moskal SF 2nd, Vaisman M, et al. Loss of heterozygosity on chromosome 11 q13 in two families with acromegaly/gigantism is independent of mutations of the multiple endocrine neoplasia type I gene. J Clin Endocrinol Metab 1999;84:249-56.

29. Takino $\mathrm{H}$, Herman $\mathrm{V}$, Weiss $\mathrm{M}$, Melmed S. Purine-binding factor (nm23) gene expression in pituitary tumors: marker of adenoma invasiveness. J Clin Endocrinol Metab 1995;80:1733-8.

30. Jacks T, Fazeli A, Schmitt EM, Bronson RT, Goodell MA, Weinberg RA. Effects of an Rb mutation in the mouse. Nature 1992;24;359:295-300

31. Zhu J, Leon SP, Beggs AH, Busque L, Gilliland DG, Black PM. Human pituitary adenomas show no loss of heterozygosity at the retinoblastoma gene locus. Clin Endocrinol Metab 1994;78:922-7.

32. Lidhar, K. Korbonits M, Jordan S, Khalimova Z, Kaltsas G, Lu X, et al. Low expression of the cell cycle inhibitor p27Kipl in normal corticotroph cells, corticotroph tumors, and malignant pituitary tumors. J Clin Endocrinol Metab 1999;84:3823-30.

33. Levy A, Hall L, Yeudall WA, Lightman SL. p53 gene mutations in pituitary adenomas: rare events. Clin Endocrinol (Oxf) 1994;41:809-8.

34. Pei L, Melmed S. Isolation and characterization of a pituitary tumor-transforming gene (PTTG). Mol Endocrinol 1997; 11:433-41.

35. Zhang $X$, Horwitz GA, Prezant TR, Valentini A, Nakashima $M$, Bronstein MD, et al. Structure, expression, and function of human pituitary tumor-transforming gene (PTTG). Mol Endocrinol 1999:13:156-66.

36. Heaney AP, Singson R, McCabe CJ, Nelson V, Nakashima M, Melmed S. Expression of pituitary-tumour transforming gene in colorectal tumours. Lancet 2000:355:716-9.

37. Zhang X, Horwitz GA, Heaney AP, Nakashima M, Prezant $T R$, Bronstein MD, et al. Pituitary Tumor Transforming Gene (PTTG) expression in pituitary adenomas. J Clin Endocrinol Metab 1999;84:761-7.

38. McCabe CJ, Khaira JS, Boelaert K, Heaney AP, Tannahill LA, Hussain $S$, et al. Expression of pituitary tumour transforming gene (PTTG) and fibroblast growth factor-2 (FGF-2) in human pituitary adenomas: relationships to clinical tumour behaviour. Clin Endocrinol
2003;58:141-50.

39. Zou H, McGarry TJ, Bernal T, Kirschner, MW. Identification of a vertebrate sister-chromatid separation inhibitor involved in transformation and tumorigenesis. Science 1999:285:418-22.

40. Nasmyth K. Segregating sister genomes: the molecular biology of chromosome separation. Science 2002;297:559-65.

41. Yu R, Lu W, Melmed, S. Overexpressed pituitary fumor transforming gene (PTTG) causes aneuploidy in live human cells. Endocrinology 2003;144:4991-8.

42. Carney JA, Gordon H, Carpenter PC, Shenoy BV, Go VL. The complex of myxomas, spotty pigmentation, and endocrine overactivity. Medicine 1985;64:270-83.

43. Yen RS, Allen B, Ott R, Brodsky $M$. The syndrome of right atrial myxoma, spotty skin pigmentation, and acromegaly. Am Heart J 1992;123:243-4.

44. Stratakis CA, Carney JA, Lin JP, Papanicolaou DA, Karl $\mathrm{M}$, Kastner DL, et al. Carney complex, a familial multiple neoplasia and lentiginosis syndrome. Analysis of 11 kindreds and linkage to short arm of chromosome 2. J Clin Invest 1996;97:699-705.

45. Casey M, Mah C, Merliss AD, Kirschner LS, Taymans SE, Denio, et al. Identification of a novel genetic locus for familial cardiac myxomas and Carney complex. Circulation 1998:98:2560-6.

46. Gadelha MR, Une KN, Rohde K, Vaisman M, Kineman RD, Frohman LA. Isolated familial somatotropinomas: establishment of linkage to chromosome 1 lq13.1-1 1q13.3 and evidence for a potential second locus at chromosome 2p16-12. J Clin Endocrinol Metab 2000;85:707-14.

47. Berezin M, Karasik A. Familial prolactinoma. Clin Endocrinol 1995;42(5):483-6.

48. Shimon I, Hinton DR, Weiss MH, Melmed S. Prolactinomas express human heparin-binding secretory transforming gene (hst) protein product: marker of tumour invasiveness. Clin Endocrinol 1998;48:23-9.

49. Heaney AP, Fernando M, Melmed S. Functional role of estrogen in pituitary tumor pathogenesis. Clin Invest 2002;109(2):277-83.

50. Shimon I, Huttner A, Said J, Spirina OM, Melmed S. Heparin-binding secretory transforming gene (hst) facilitates rat lactotrope cell tumorigenesis and induces prolactin gene transcription. J Clin Invest 1996;97:187-95.

51. Sarkar DK, Gottschall PE, Meites J. Damage to hypothalamic dopaminergic neurons is associated with development of prolactin-secreting pituitary tumors. Science 1982;218:684-6.

52. Friedman E, Adams EF, Hoog A, Gejman PV, Carson E, Larsson $C$, et al. Normal structural dopamine type 2 receptor gene in prolactin-secreting and other pituitary tumors. J Clin Endocrinol Metab 1994;78:568-74.

53. Ben-Shlomo A, Miklovsky I, Ren SG, Yong WH, Heaney AP, Culler MD, et al. Leukemia inhibitory factor regulates prolactin secretion in prolactinoma and lactotroph cells. J Clin Endocrinol Metab 2003;88:858-63.

54. Fiorentini C, Guerra N, Facchetti M, Finardi A, Tiberio L, Schiaffonati $L$, et al. Nerve growth factor regulates dopamine $D(2)$ receptor expression in prolactinoma 
cell lines via p75(NGFR)-mediated activation of nuclear factor-kappaB. Mol Endocrinol 2002;16:353-66.

55. Paez-Pereda M, Giacomini D, Refojo D, Nagashima AC, Hopfner U, Grubler Y, et al. Involvement of bone morphogenetic protein 4 (BMP-4) in pituitary prolactinoma pathogenesis through a Smad/estrogen receptor crosstalk. Proc Natl Acad Sci USA 2003; 100:1034-9.

56. Finelli P, Pierantoni GM, Giardino D, Losa M, Rodeschini $\mathrm{O}$, Fedele $\mathrm{M}$, et al. The High Mobility Group A2 gene is amplified and overexpressed in human prolactinomas. Cancer Res 2002;62:2398-405.

57. Caccavelli L, Cussac D, Pellegrini I, Audinot V, Jaquet P, Enjalbert A. D2 dopaminergic receptors: normal and abnormal transduction mechanisms. Horm Res 1992;38(1-2):78-83.

58. Verges B, Boureille F, Goudet $P$, Murat A, Beckers A, Sassolas $G$, et al. Pituitary disease in MEN type 1 (MEN 1): data from the France-Belgium MENI multicenter study. $\mathrm{J}$ Clin Endocrinol Metab 2002;87:457-65.

59. Schmidt MC, Henke RT, Stangl AP, Meyer-Puttlitz B, Stoffel-Wagner B, Schramm J, et al. Analysis of the MEN 1 gene in sporadic pituitary adenomas. J Pathol 1999;188: 168-73.

60. Dahia PLM, Grossman AB. The molecular pathogenesis of corticotroph tumors. Endo Rev 1999;20:136-55.

61. Yano H, Readhead C, Nakashima M, Ren SG, Melmed S. Pituitary-directed leukemia inhibitory factor transgene causes Cushing's syndrome: neuro-immuneendocrine modulation of pituitary development. Mol Endocrinol 1998;12:1708-20.

62. Huizenga NA, de Lange P, Koper JW, Clayton RN, Farrell WE, van der Lely AJ, et al. Human adrenocorticotropinsecreting pituitary adenomas show frequent loss of het- erozygosity at the glucocorticoid receptor gene locus. J Clin Endocrinol Metab 1998;83:917-21.

63. Antonini SR, Latronico AC, Elias LL, Cukiert A, Machado $H R$, Liberman B, et al. Glucocorticoid receptor gene polymorphisms in ACTH-secreting pituitary tumours. Clin Endocrinol (Oxf) 2002;57:657-62.

64. Theodoropoulou M, Arzberger T, Gruebler Y, JaffrainRea ML, Schlegel J, Schaaf L, et al. Expression of epidermal growth factor receptor in neoplastic pituitary cells: evidence for a role in corticotropinoma cells. J Endocrinol 2004; 183:385-94.

65. Chaidarun SS, Klibanski A. Gonadotropinomas. Semin Reprod Med 2002;20:339-48.

66. Pagotto U, Arzberger T, Theodoropoulou M, Grubler Y, Pantaloni C, Saeger W, et al. The expression of the antiproliferative gene ZAC is lost or highly reduced in nonfunctioning pituitary adenomas. Cancer Res 2000;60:6794-9.

67. Gittoes NJ. Current perspectives on the pathogenesis of clinically non-functioning pituitary tumours. J Endocrinol 1998;157:177-86.

68. Pereira-Lima JF, Marroni CP, Pizarro CB, Barbosa-Coutinho LM, Ferreira NP, Oliveira MC. Immunohistochemical detection of estrogen receptor alpha in pituitary adenomas and its correlation with cellular replication. Neuroendocrinology 2004;79:119-24.

\section{Endereço para correspondência:}

Marcello D. Bronstein

Av. 9 de Julho 3858

01406-100 São Paulo, SP

E-mail: mdbronstein@uol.com.br 